\title{
(Re)Conceptualizing Design Approaches for Mobile Language Learning
}

\author{
DeBra Hoven \\ Athabasca University \\ AgNiESZKa PALALAS \\ George Brown College
}

\begin{abstract}
An exploratory study conducted at George Brown College in Toronto, Canada between 2007 and 2009 investigated language learning with mobile devices as an approach to augmenting ESP learning by taking learning outside the classroom into the real-world context. In common with findings at other community colleges, this study identified inadequate language proficiency, particularly in speaking and listening skills, as a major barrier for ESL college learners seeking employment, or employers hiring and retaining immigrants as employees (CIITE, 2004; Palalas, 2009). As a result of these findings, language support was designed to provide English language instruction going beyond the standard 52-hour course: a hybrid English for Accounting course encompassing in-class, online and mobile-assisted ESP instruction. This paper reports on the pilot study of the mobile component of this re-designed course, which represents the first stage of an on-going Design-Based Research (DBR) study. Discussion is also offered of a new learning theory which we have called Ecological Constructivism (Hoven, 2008; Jakobsdottir, McKeown \& Hoven, 2010), devised to incorporate the multiple dimensions of Ecological Linguistics and Constructivism in the situated and context-embedded learning engendered by these new uses of mobile devices.
\end{abstract}

\section{KEYWORDS}

Mobile Assisted Language Learning (MALL), Learning Theory, Constructivism, Learner-created Content, Mobile Instructional Design

\section{INTRODUCTION}

The effective design of curriculum, content and delivery of vocational English for Specific Purposes (ESP) language courses for immigrants to a dominant English-speaking country has long been a contentious and problematic area for ESL professionals (Dudley-Evans \& St John, 1998; Gatehouse, 2001; Hutchinson \& Waters, 1987; Strevens, 1988).

The ESP course for accounting students reported on here resulted from a previous two-year process of research and instructional design revisions at George Brown College in Toronto, Canada. In this earlier benchmarking study, language requirements of entry level accounting positions in the authentic Canadian workplace were established using the Canadian Language Benchmark (CLB) framework. The $\mathrm{CLB}^{1}$ is "a set of descriptive statements about successive levels of achievements on the continuum of ESL performance" (Pawlikowska-Smith, 2000, p.viii). Data from eight companies were collected through job shadowing and interviews providing information on speaking, listening, reading and writing as well as sociocultural competencies essential in the accounting workplace. At the same time, language requirements of the corresponding program at the College as well as the students' language 
proficiency were measured. Resulting CLB numeric values, from CLB 1 to CLB 12, were juxtaposed, revealing considerable gaps between students' language proficiency and the language necessary for academic and workplace success. The average gap between students' English language proficiency and the workplace requirement for speaking was 1.9 CLB and for listening -1.6 CLB. However, a number of students needed to improve their oral and aural skills by up to 4 CLB levels to meet the minimum workplace requirement of CLB 8 . As it takes approximately 380 hours for an individual with graduate level education to progress from CLB 6 to CLB 7 (Alberta Learning, 2004), the recommended ESP intervention had to provide English language instruction going beyond the standard 52-hour course. Further examination of specific learner needs was completed through focus groups and interviews with faculty and students. In common with research studies at other community colleges, this benchmarking project identified inadequate language proficiency, in particular, insufficient speaking and listening skills, as a primary barrier for ESL college learners seeking employment, or employers hiring and retaining immigrants as employees (CIITE, 2004; Palalas, 2009).

On the basis of these data, the decision was made to create a language support course that would focus on speaking and listening, while providing flexible language practice expanding beyond the classroom time and space. To ensure extended additional language practice, the Mobile-Assisted Language Learning (MALL) component was introduced. Hence, the resulting English for Accounting course was designed to encompass in-class, online and mobileassisted ESP instruction, surpassing the standard 52 in-class hours. The content and delivery methods of this adjunct language course reflected the benchmarking findings and the specific needs of the College ESP students. In response to the benchmarking findings, the curriculum of this course was designed to address primarily oral and aural skills. The effectiveness of this approach was evaluated through focused research.

The exploratory study presented here examined the mobile component of the blended course and researched language learning with mobile devices as an approach to augmenting ESP learning by expanding it outside the classroom. While the mobile component of the course aimed at exploring the inherent audio and video capabilities of mobile devices, some text-based blogging, emailing and note-taking activities were also part of the mix. A number of questions pertaining to the effectiveness of Mobile-Assisted Language Learning and students' experience with mobile technology were investigated. This study became the pilot stage of an ongoing Design-Based Research (DBR) study which is continuing to examine questions surrounding the effectiveness of a range of instructor- and learner-created mobile resources designed to support improved vocational English learning and proficiency (see Figure 1 below for an overview of the timelines of this DBR study). The design of both the study and the curriculum and resources on which it is based has necessitated a close examination of the theoretical framework underpinning the researchers' thinking, which has moved from Social Constructivism in the initial stage, through Sociocultural Theory (SCT) to the evolution of our current theory of Ecological Constructivism. This process will be described below. 
Figure 1

Timelines \& evolution of the DBR study

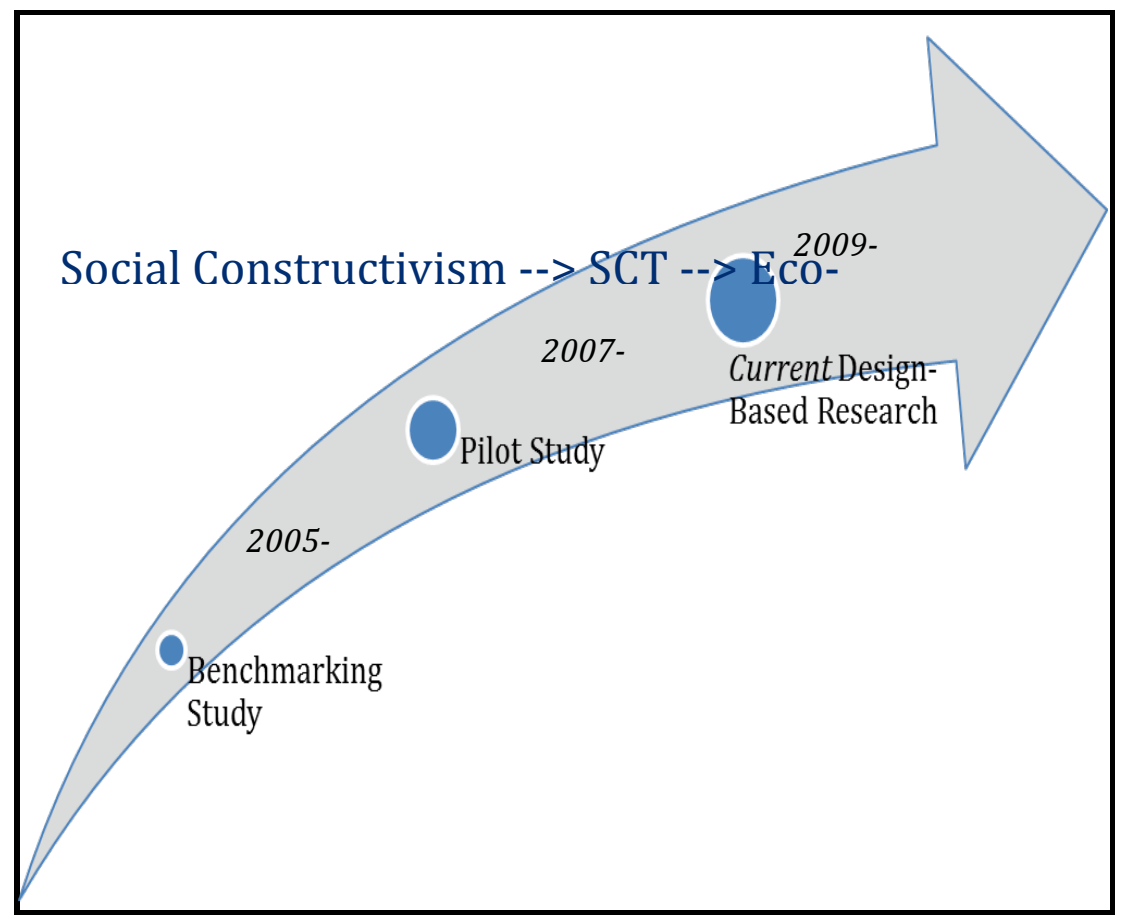

\section{THEORETICAL FRAMEWORK}

In this section of the paper, we introduce Ecological Constructivism and provide an overview of the development of this theory, together with the choice of methodological approach (DBR), which followed from this. Finally, this section outlines the progress of research and theory underpinning the process of language learning through the use of mobile devices. Ecological Constructivism as a theory encompasses general learning and language learning more specifically, while also engendering an ecological approach to research methodology. Ecological Constructivism provides a lens through which to view holistically the systems of language (Halliday, 1993; Wells, 1994), the processes of language learning, the systems of interaction among different participants or interactors, and a research approach to exploring the mutual exchanges within these emergent systems.

As well as providing extensive explanatory power for learning deriving from the interaction between individuals and their environments or contexts, an ecological perspective on Constructivism allows for incorporation of both a focus on the individual's process of learning as advocated by Piaget (1971) and theories of learning embodied in Sociocultural Theory (SCT) and other forms of Vygotsky-derived Constructivism in which a greater emphasis is placed on the interaction and co-creation of knowledge among groups and networks of human learners. As Lam and Kramsch in 2003 (p. 144) mention in reference to second language acquisition, "the recent metaphor of ecology attempts to capture the interconnectedness of psychological, social, and environmental process in SLA". It is this interconnectedness between processes internal to individuals and the environment in which they exist and interact that forms one of the principles of Ecological Constructivism.

In 2000, van Lier already proposed that not all cognition and learning can be explained by processes inside the head of the learner, but rather in concert with social processes. Learning is perceived, for example, as "the perceptual and social activity of the learner, and 
particularly the verbal and nonverbal interaction in which the learner engages" (van Lier, 2000 , p. 246). Learning and cognition thus depend on "both representational (schematic, historical, cultural, and so on) and ecological (perceptual, emergent, action-based) processes and systems (Neisser, 1992 as cited by van Lier, 2000, p. 247). For the purposes of this discussion, we are using the term "ecological linguistics" to encompass this view of language and the concomitant sites and processes (semiotic systems) of language learning. From an ecological linguistic stance, language learners learn to process meaning through a fluid system of mediated verbal and non-verbal relationships which are contingent on affordances in their context and environment. These relationships may be mediated by other learners, more sophisticated users of the language, signs and nuances in the context, technology-based resources and the technological tools themselves. Language is therefore emergent and dynamic, as learners use and create authentic language, both purposefully and incidentally, on the basis of their perceptions of, interactions with and action upon affordances found in their learning and language environment (Hoven, 1997; Lafford, 2009; van Lier, 2000).

The trigger for the evolution of our Ecological Constructivist perspective on learning theory came from the discussion of various branches or manifestations of Constructivism by Davis and Sumara $(2002 ; 2003)$ and Proulx (2006). In their explanations of the differences and similarities and derivations of these branches, these authors mention the difference in translation and thus interpretation of the term "construct," taking us back to the English translation of the original French verb "construire" which can be translated as either "to construct" or "to construe". While the former translation implies an "architectural," predetermined, deliberate, and explicit construction of meaning, the latter emphasizes a more "biological", contingent, tacit, unfolding, ever-evolving process as represented by the emergence of an organic structure or organism. It is this latter interpretation, which we feel better, accommodates contemporary understandings of the interaction among the different systems of language commonly termed "ecological linguistics" (Lam \& Kramsch, 2003; van Lier, 2000; 2004; Lafford, 2009), and theories of learning which come under the umbrella of Constructivism, Sociocultural Theory (Lantolf, 2000, among others) and Connectivism (Downes, 2007; Siemens, 2005; 2007). At the same time, Ecological Constructivism provides a metaphor that describes an approach which seems appropriate for investigating language learning (van Lier, 2000, p. 247).

The Design-Based Research approach to this investigation, discussed in detail below, is an example of contemporary implementations of research methodology within an ecological paradigm. Ecological Constructivism has guided the design of the mobile language learning resources and interactions engendered through mobile devices which have been created for, with and by learners in this project. When a need to redesign the original MALL solutions was established and a theory of learning was being re-considered for this project, neither SCT nor any of the existing branches of Constructivism seemed to have the capacity to adequately describe and predict the kinds of actions, interactions and learning inherent in the dynamic creation of content by learners using mobile devices in this project. For similar reasons, an ecological approach to the investigation of the context-embedded process of learning appeared to be necessary to the integrity of the study presented here.

\section{DESIGN-BASED RESEARCH OVERVIEW}

The following definition of DBR, proposed by Wang and Hannafin (2005), captures the salient characteristics of this method:

[DBR is a]... systematic but flexible methodology aimed to improve educational practices through iterative analysis, design, development, and 
implementation, based on collaboration among researchers and practitioners in real-world settings, and leading to contextually-sensitive design principles and theories. (p. 7)

Van den Akker and his colleagues (2006) further defined DBR by describing it as practical, interventionist, iterative, both process-and theory-oriented as well as informed by practitioners. It is these characteristics of collaboration of participants in the context of progressive iterations and refinements and the reflexivity of theory and praxis that define DBR as a research methodology, which fits well with Ecological Constructivism.

Figure 2

The ILDF model (Bannan, 2009, p. 54)

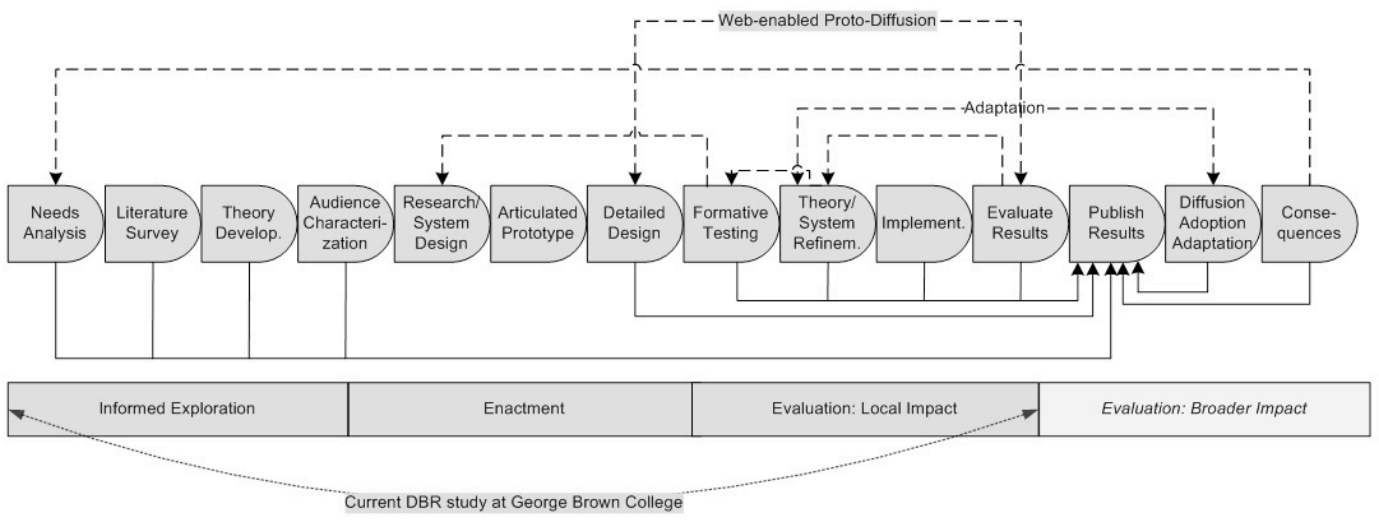

The Informed Exploration phase, which derives from the outcomes of the pilot study reported in this article, forms, according to the Integrative Learning Design Framework (ILDF) (Bannan, 2009), the first of the four phases of a DBR study. The ILDF model, adopted for this study, integrates processes from the fields of "instructional design, object oriented software development, product development and diffusion of innovations and educational research" to offer a systematic framework guiding researchers toward "more rigorous, research-based cycles within a technology-based instructional design effort" (p. 53). The ILDF model suggests applicable questions and research methods for its four phases of (1) Informed Exploration, (2) Enactment (3) Evaluation: Local Impact, and (4) Evaluation: Broader Impact (Figure 2).

Informed Exploration includes a comprehensive literature review, closer audience characterization, investigation of comparable design solutions in equivalent MALL contexts and qualitative data collection via interviews with experts and language teachers. The purpose of this first phase is to produce a theoretical construct which will guide the design experiment. Informed by the pilot study and the Benchmarking study which preceded it, the process of theoretical conceptualization has led to the exploration of Ecological Constructivism as the basis for the pedagogical approach to MALL design. The ecological metaphor has since guided the on-going phase of the larger DBR study: the Enactment phase, as well as providing an useful metaphor for the design of the research study. 
We now turn to a more detailed discussion of the evolution of our thinking in the development of Ecological Constructivism as an appropriate theory of learning which accommodates the melding of Social Constructivism, Sociocultural Theory and Ecological Linguistics as well as providing a useful metaphor for the design of the research study. In the design of the initial Benchmarking study (Figure 1 above), the learning theory which directed the selection of questions to investigate and the approach to design of the research study was Social Constructivism.

As Davis and Sumara $(2002 ;$ 2003) observe, the term "constructivism" encompasses a number of discourses related to cognition. The subject-centered discourses, rooted in the work of Piaget, and manifest as either Cognitive or Radical Constructivism, differ in focus from the social accounts. The latter, including Situated, Social, Cultural, Sociocultural, and Critical Constructivism, are more aligned with the work of Vygotsky. Although they differ in their orientation and emphases, constructivist discourses share three points of agreement: (1) learning being conceived as complex, dynamic, and continuous active processes of ongoing adaptation; (2) "these dynamics [being] regarded as the means by which the cognizing agent ...maintains its coherence (Davis \& Sumara, 2003, p. 125); and (3) a rejection of representationist theories such as behaviorist and mentalist accounts of cognition (Davis \& Sumara, 2003). Many educators and theorists influenced constructivism indirectly (e.g., Dewey, Kant, Marx, von Glasersfeld, Bruner, Lave \& Wenger) with Piaget's cognitive developmental theory forming the basis of the subject-oriented constructivist accounts. The epistemological work of Piaget offered considerable insight into human learning. The central idea is that human learning is constructed or construed upon the foundation of previous knowledge, through "progressive equilibrium of assimilation and accommodation" (Piaget, 1971, p. 108). Such learning is an active process through which the learner updates his/her knowledge based on the relevant elements in the new information and their consistency with prior and emerging knowledge. According to Piaget's theory of individual learning the knower is "engaged in the unrelenting project of assembling a coherent interpretive system, constantly updating and revising explanations and expectations to account for new experiences" (Davis \& Sumara, 2003, p. 413). In other words, individuals create subjective knowledge on the basis of their own experiences.

By contrast, Vygotsky (1978) proposed a paradigm of learning that emphasizes collective phenomena and the relationship between subjectivity and objectivity. Social constructivism stemmed from his proposition that meaning is socially and culturally mediated. Vygotsky (1978) asserted that knowledge is first constructed in a social context and is subsequently appropriated by individuals. Each learner is viewed as a complex multidimensional individual with unique needs and backgrounds. That uniqueness becomes an integral part of the learning process (Wertsch, 1991). Thought and language are entirely interlinked in human mental functioning and in human life (Vygotsky, 1986). In fact, the language of the culture he/she lives in and shares with others constitutes the individual. The learner as a member of a particular culture inherits language and it is learned throughout the learner's life. In the learning process, individuals contribute their unique background, culture and worldviews.

Language, which is used as a means of communication and mediation, is embedded in the sociocultural context embracing its cultural, historical and institutional dimensions (Wertsch, 1985; Wertsch, 1991). Language is an integral element of the process of socialization which "involves mastering the rules for using particular speech genres in a particular sociocultural setting" (Wertsch, 1991, p. 130). Hence, meaning is generated and transformed in sociocultural contexts, in which individuals become "collaborative meaning-makers among a group defined by common practices such as language, use of tools, values and beliefs" (Spikol, 2009, p.125). 
A social constructivist would say knowledge is not merely constructed but it is coconstructed. Only with support of, or in collaboration with others, can cognitive structures be developed. The notion of a "zone of proximal development" (ZPD) plays a vital role in the learning process. Vygotsky defines the ZPD as the distance between a learner's "actual developmental level as determined by independent problem solving and the level of potential development as determined through problem solving under adult guidance or in collaboration with more capable peers" (Vygotsky, 1978, p. 86). Consequently, by use of scaffolding techniques, instructors and peers can provide temporary support that enables learners to construct knowledge structures that are meaningful to them. Effective scaffolding is provided by a more knowledgeable person, usually but not exclusively instructors, and is optimized by social interaction.

The socio-cultural paradigm derives from Vygotsky's theory of social constructivism and as such, integrates the elements of mediation, goal-oriented learning, the Zone of Proximal Development (ZPD) and community of practice (Hoven, 1999a). Language teachers and researchers adopted these constructivist concepts, with a strong emphasis on language, mediation and learning through interaction in a community as Sociocultural Theory (SCT). Further, Vygotsky's claim that "human behavior results from the integration of socially and culturally constructed forms of mediation into human activity" (Lantolf, 2000, p. 8) highlighted the importance of a community of practice for effective language learning. According to Lantolf (2000) Sociocultural Theory sees speaking (social interaction) and the internal cognitive process of thinking as being strongly interconnected in "a dialectic unity in which publicly derived speech completes privately initiated thought" (p. 6). As also found in aural-skill-oriented literature, interactivity was identified as sine qua non by SCT: for learning to occur, repeated interaction with the context and other people is needed. In order for the learner to achieve independent performance, interactivity should be combined with the scaffolding support of a facilitator or peer (Vygotsky, 1978). The computer becomes the tool for mediation of meaning "in the form of software incorporating information, feedback, and appropriate help systems" (Hoven, 1999a, p. 96). As with language, the technology is viewed as a culturally constructed artifact enabling a mediated relationship with others and the world. As learners develop, they gain increasing control over "the meditational means made available by their culture, including language, for interpersonal (social interaction) and intrapersonal (thinking) purposes" (Lantolf, 2000, p. 6). The shift in the tools learners use to interact affects the way they communicate, which also has to be factored into the design of instruction. SCT was therefore initially considered as the framework for the pilot study because of its potential to address the cognitive process and the usage of language as an enabler of communication, the role of technology in that interaction, as well as the relationship amongst all these factors.

However, when the design of mobile resources entered the phase under discussion in this study, a few aspects of the design could not satisfactorily fit into any of the previously espoused theoretical models. Some aspects of ecological linguistics as outlined by van Lier (2000) and Lafford (2009) resonated with our need to incorporate knowing as an evolving process rather than the static entity commonly envisaged by the term "knowledge" (Proulx, 2006). At the same time, we also wanted to incorporate the concept of individuals coming to new understandings both through their own perceptions and purposeful actions as well as in collaborative co-creation with others, and the dynamic and fluid connections made possible through the use of mobile technologies. Moreover, this active learning experience had to be set in a real-life context offering potential supports and affordances.

Drawing these ideas together to form a coherent theory of learning, and as a result of the considerations discussed above, we propose that the following concepts are critical to 
construing learning, and particularly language learning, from an ecological constructivist position:

1. affordances exist as an initial state in the dynamic environment: that is, affordances are inherent properties of the human environment which is in a state of constant, often subtle change;

2. learners have the capacity to perceive, construe and act purposefully on these, both individually and in collaboration with others: the usefulness of an affordance is only manifest when a learner perceives it as salient. This perception may arise within an individual learner, in isolation from others or perception may dawn as a result of interaction or collaboration with others;

3. learning, whether individual or collaborative, emerges from and through interactions (with the perceived environment, that is affordances, with content, other novice and experienced humans or human-created devices such as mobile and other technologies);

4. the co-creation of knowing, understanding and interpretation occurs both individually and collaboratively, and these are shared reciprocally with other individuals, groups and networks (whether purposefully or incidentally), thereby bringing novel affordances into the environment which did not pre-exist, nor could they exist, without such interaction: the process of collaboration enables individuals to perceive novel affordances that could not be perceived by an individual learning in isolation;

5. individuals perceive, construe and act on affordances in the environments in which they move, collaboratively and in dynamic networks of fluidly inter-linked contexts, forming an open and permeable system - in other words, an eco-system. Systems are contingent: movement can occur in different systems simultaneously and affordances of the environment, since they are perceived differently by different learners, can be shared fluidly between or among systems.

To elaborate the points above in relation to the uses of mobile technologies for language learning, each of these elements will now be discussed. Firstly, the recurring concept of affordances can be traced in the literature back to Gibson (1986). In second language learning van Lier has defined an affordance as " ... a particular property of the environment that is relevant - for good or ill - to an active, perceiving organism in that environment" (2000, p. 252). In language learning occurring in the presence of technology, affordances are only realized by the interaction of a learner with that technology and/or other humans and content, and the ways in which these in turn allow ("afford") access to learning and knowing. Learners may select from among different perceived affordances for different purposes: an expert user of a mobile device may browse multiple dictionaries across different websites looking for vocation-specific applications of a particular term or phrase, or may use the hunter-gatherer technique to collect several examples for a group-based collaborative task, or use the hunt-and-kill technique to locate an audio recording of a specific word.

Mobile technology can be seen as a source of affordances if the MALL activities are designed with the concept of affordances in mind. Affordances can therefore become learning opportunities when:

- they are available in the environment, with the pedagogical implication that the objects or resources available in the environment (e.g. visuals to support audio discourse) have to be linguistically rich enough for selection by diverse learners;

- they are salient enough to be noticed by learners and learners are actively and purposefully looking for linguistic material (the learner must have a purpose for perceiving and using those affordances and the tasks must 
have a well-defined linguistic goal);

- some guidance is provided or mediated through interaction with another student, a teacher or the directions or design of a mobile activity;

- they facilitate relevant and enhanced action, which might necessitate appropriate scaffolding derived from communication with others or access to alternative language resources by means of mobile devices.

Such learning opportunities might not be planned, but rather the learning emerges and evolves as students find various resources and affordances. Learners become more active, more autonomous and more collaborative as they contribute to their own learning, and that of others as they co-construct meaning for themselves and others. Based on these premises, our design of MALL learning opportunities comprising interaction among technology, context and people will allow the negotiation, creation and sharing of meaning through which the process of learning and knowing develops. The iterative phases and evolving design of this DBR study will enable the researchers to identify which affordances of the MALL environment are more often perceived and acted upon by learners. This will contribute to the design of a MALL environment that is more effective for language learning. In this way we feel it is both possible and timely to bring together the disparate, though not un-related fields of biology, from where Piaget construed his understandings of learning, and psychology, from which Vygotskyan theories of learning have been constructed. The next section outlines the research findings and theoretical basis for the uses of mobile devices in learning.

\section{MOBILE LEARNING LITERATURE: BRIEF OVERVIEW}

The use of mobile devices in language learning in general and ESP in particular is a relatively new phenomenon and research studies on their effectiveness for this purpose and the resulting literature are still relatively scarce. When creating mobile resources for this purpose, it was therefore crucial to consider both affordances and limitations of the handheld technologies as identified by studies in this and other fields. Our design decisions drew on the characteristics inherent to mobile learning which "can be spontaneous, personal, informal, contextual, portable, ubiquitous (available everywhere) and pervasive (so integrated with daily activities that it is hardly noticed)" (Kukulska-Hulme, 2005, p. 2). Moreover, mobile digital tools can enable enhanced connectivity with information and other users, thereby promoting the socio-cultural dimension of learning. They can also facilitate cognitive processes by making information available and presented in a way which avoids learner memory overload (Pachler, 2009). Mobile learning offers learners on-demand flexibility "congruent with learners' increasingly mobile, always-connected lifestyles" (Kukulska-Hulme \& Shield, 2008b, p. 249). It also enables "continuity or spontaneity of access and interaction across different contexts of use" (Kukulska-Hulme \& Shield, 2008a, p. 273).

While fewer time and space constraints (Nah, White, \& Sussex, 2008), combined with ownership and control of what, when and where to learn (Laurillard, 2007) add to the flexibility of mobile learning, immediate access to people and information enhances interactivity. Flexible interaction with teachers, experts and peers offered in a more selfpaced collaborative environment can further promote learning. Additionally, KukulskaHulme and Pettit (2009) mention convenience and portability, utilizing dead time productively (e.g., when commuting), being able to connect and interact, affordability, access to up-to-date material, and multimedia options. Mobile technologies also allow for organizing learning into "manageable chunks" (Chinnery, 2006), and reinforcing oral and aural skills (Abdous, Camarena, \& Facer, 2009). Rosell-Aguilar (2007) revisits several MALL studies and completes the list above with the additional advantages of attractiveness, motivation, and access to resources integrating in-class and out-of-class learning. In 
addition to these characteristics, mobile devices also enabled our students to co-create and contribute their own content to the on-the-go and just-in-time resources. It is this aspect of mobile device use in particular which has shifted our theoretical thinking.

In terms of limitations of mobile technologies which may have an impact on the design of MALL resources, Thornton and Houser (2005) reported slow downloading speeds, small mobile phone screen sizes, and the limited control functions of mobile phones. The caveat list also includes excessive mobile phone and network expenses (Kiernan \& Aizawa, 2004; Kukulska-Hulme \& Shield, 2008a), difficulties typing English and completing assignments on the small devices, or difficulty of listening effectively in noisy public places. In addition, Kukulska-Hulme and Pettit (2009) mention technical and ergonomic limitations such as an inadequate quality of some microphones and speakers, awkward controls on cheaper devices, short battery life, as well as a lack of wi-fi (wireless network) access in many locations. Mobile devices may enable interaction; however, the resulting communication can be less meaningful due to the limited depth of thinking and learning, distraction, and everything having to be "short and small" (Kukulska-Hulme \& Pettit, 2009). In response to the findings of mobile learning literature identifying the difficulties with small keyboards, the small screen size and cost of connectivity as primary barriers to mobile learning, we decided to use the mobile technology principally, but not exclusively, for the provision of prerecorded listening content.

The design of mobile activities was initially guided primarily by Social Constructivist principles with emphasis on collaborative tasks, interactivity, scaffolding and mediations through language and through mobile technology. At the same time, some of the activities targeting vocabulary comprehension and designed principally for practice in "dead time" (such as that experienced by learners during commute or wait time) were behaviourist in approach. It became evident during the pilot study that the pedagogical framework underpinning the design of MALL resources required further investigation. As discussed earlier, the learning theory that evolved to form the basis for the design of the MALL resources, Ecological Constructivism, resulted from the progression through the consecutive stages of our research study to date. The pilot study that led to the re-conceptualization of our approach and resulted in the design of the resources based on the principles of Ecological Constructivism will be detailed below.

\section{THE PILOT STUDY}

\section{Background}

As mentioned in the introduction, the hybrid ESP course for Accounting students resulted from two years of language benchmarking research at George Brown College. This innovative blend of in-class, online, and mobile learning was piloted with a group of L2 learners, paving the way for the ongoing DBR study and its investigation of effective MALL designs. Guided by the language benchmarking findings, the course focused on speaking and listening skills, with a sufficient amount of workplace writing and reading practice to provide an integrative language learning environment. To accommodate students' exceptionally busy schedules and respond to their particular needs for flexible learning with fewer time and place constraints, a hybrid solution was developed. The course blended two hours of in-class learning with added instruction and practice both online and via mobile devices. It is the MALL component, via mobile devices, which forms the substance of the study reported here.

Over the 15 weeks of this non-credit ESP course pilot, students were encouraged to complete all mandatory activities and select from optional content for supplementary individualized practice. While speaking competencies were the main thrust of the in-class module, the online WebCT modules encompassed materials and assessments addressing primarily listen- 
ing, grammar, as well as some reading and writing competencies. The MALL component was offered through iTouch devices that were loaned to students for the length of the pilot; however, some students chose to also use their own handheld devices. The following section provides more details on the design of the blended ESP course and the language resources it offered.

\section{Design of the English for Accounting ESP Course}

The course was designed to offer ESP content through a combination of both face-to-face and online modes, whereas aural practice was provided via mobile devices. All language resources were created with the help of Accounting faculty together with ESL practitioners and an instructional designer. The course curriculum incorporated materials and scenarios from both the College Accounting courses as well as examples from actual Canadian workplaces, previously collected during the benchmarking study. When meeting face-to-face in the classroom, students were encouraged to practice their speaking through communicative problem-based tasks. All in-class tasks and activities drew from the Accounting program curriculum or the accounting workplace scenarios (including accounting vocabulary, job search issues and techniques, office etiquette, interwoven with contextual grammar practice, workplace writing, learning strategies, and pronunciation). The in-class elements included group and individual pronunciation practice, group information gap tasks as well as individual presentations on accounting issues. In addition, students had a chance to discuss articles and podcasts presented with the use of WebCT and mobile technologies. The time spent interacting face-to-face was, indeed, the only forum for both formal and informal oral discourse as well as the only opportunity to practice spontaneous speech and interactive listening.

The online component of English for Accounting, offered through the WebCT platform, provided a selection of mandatory and optional resources, which encompassed individual reading and writing tasks reflecting the content and competencies required by the Accounting classroom and the workplace, grammar drills, vocabulary and grammar quizzes, as well as interactive projects and discussions via the online forum. Discussion forum topics were organized around the audio and video podcasts created by the project for students' mobile devices. Multiple links to online ESL and accounting dictionaries and other free ESL resources were made available. To ensure flexible access to the materials, all audio and video podcasts created for retrieval with mobile devices were alternatively offered in WebCT.

Thirty audio and video podcasts were produced in-house to ensure consistency with the course learning outcomes. These were recorded professionally with the help of the College A/V technologist, George Brown College Performing Arts students, three Accounting Department employees, and ESL practitioners. All scripts for the video and audio podcasts were based on actual workplace situations, dialogues, and terminology. The materials were then refined by both the accounting and ESL experts to exemplify the language used in the accounting workplace and to deliver language instruction at the CLB level appropriate for this group of students. These podcasts and vodcasts were provided to students for on-thego retrieval and practice and could be downloaded either directly from the WebCT course site or through iTunes. The content encompassed activities targeting competencies identified as crucial yet lacking amongst the accounting L2 students, as determined through the language proficiency tests in the earlier benchmarking study. Accounting terminology and definitions of financial concepts (see Appendix A for examples) were collected from two selected Accounting textbooks and recorded in 5-10 minute segments to allow on-demand retrieval and practice of terms. These podcasts were then further refined to include the repetition of key terms, vocabulary recollection based on definitions, and aural spelling practice. 
Audio vocabulary quizzes were also developed to include key accounting terms as well as more generic vocabulary. To encourage the development of conversational and sociocultural competencies, "Accounting Workplace" vodcasts were created, all of which could be downloaded via iTunes. These 2-8 minute-long videos depicted everyday workplace behaviour and issues, with an element of humor added to some of the clips. Students watched the vodcasts at their convenience and subsequently participated in the online text-based discussion of the issues presented in them. Students were also asked to answer comprehension questions based on these workplace scenarios.

Other general ESL podcasts and open source video resources were recommended and available to students through the WebCT site. These included selected ESLpod (n.d.), Business English Pod (n.d.), iTunesU (n.d.) and TED episodes (n.d.) as well as digitized recordings of Whaddaya Say audio activities. Access through the mobile devices to supplementary resources such as online dictionaries was also encouraged.

To provide a forum for interactive discussion of the Accounting vodcasts, students were asked to use their mobile devices for blogging. A class Wordpress blog was generated where students were to record their written reflections. All in all, the design and re-design of the MALL resources was informed by the feedback collected throughout the pilot and by an ongoing exploration of mobile learning literature.

\section{Purpose and Method}

As stated earlier, the ESP blended course stemmed from an in-depth investigation into the language proficiency of L2 students at GBC and their specific needs. A number of questions pertaining to content design and delivery, selection and usage of mobile tools, and the role of teachers and learners had to be explored to understand the experiences and preferences of students vis-à-vis the design of the MALL resources in the ESP course context. The key questions asked at the pilot stage of the DBR study included the following:

1. are the mobile devices an appropriate technology for language learning?

2. what affordances and caveats of the mobile devices are pertinent to the learning experience and outcomes?

3. do students improve their language proficiency when learning with mobile devices?

4. do learners consider mobile learning technologies to be user-friendly?

5. do learners find MALL activities effective and enjoyable?

These overarching research questions were addressed through student surveys, interviews and a focus group, as well as the CLB language proficiency test. By exploring first-hand accounts of student-participants' experiences and perceptions, the study set the foundations for future inquiry into the effective MALL design.

\section{Participants}

The purposive sampling method was employed to recruit participants for the pilot study. While twelve students volunteered to participate in the full blended version of the course, eight other students opted for the online component only. It is worth noting, on the one hand, that all twelve blended-version students completed the course and participated both in the feedback collection as well as the language proficiency tests. The online students on the other hand, while demonstrating interest in the WebCT activities, did not exhibit the same level of engagement overall, nor did they participate in any assessment or feedback exchange. The resulting research sample size for the pilot study was, therefore, twelve $(n=12)$ mobile students who participated in all components of the hybrid ESP course.

The twelve participants were all internationally trained professionals studying in an Account- 
ing program at George Brown College. These adult, non-traditional learners came from diverse cultural and educational backgrounds; however, they were all of 'Confucian-heritage,' in that they came from China, Korea, Vietnam and Japan. There were two male and ten female learners and the average age of the group was 33. They all emphasized their particularly busy schedules resulting from the multiplicity of school, work and family-related responsibilities with which they had to cope. Regardless of those limitations, the students selfselected for the pilot, reporting a need for additional ESP support.

\section{Data Collection and Analysis}

The effectiveness of the m-learning resources and approach were evaluated using qualitative and quantitative measures. These included semi-structured interviews with students, conducted mid-way through the pilot, and a focus group followed by an online survey (a Zoomerang survey incorporating both quantitative and qualitative questions), both administered in the final week of the course. The feedback gathered from respondents was distilled to provide a record of perceived learning and satisfaction with the mobile aspect of the course, as seen through the eyes of learners. While all quantitative responses to the final survey questions were analyzed using Excel, transcripts of the interviews and focus group were coded for emerging themes using NVivo analytic qualitative software and subsequently validated by an independent researcher. To provide insight into our students' progress, their language proficiency was measured pre- and post-treatment using the Canadian Language Benchmark Placement Test (CLBPT), widely adopted as a valid and reliable ESL evaluation instrument. The CLBPT results were subsequently triangulated through the use of in-class tests focusing on the learning outcomes targeted in the course.

In order to further enrich our understanding of the ESP mobile experience, feedback from the classroom teacher was also obtained through bi-weekly pilot update interviews of 15 to 20 minutes in length, as well as ad-hoc e-mail correspondence reporting on students' issues and successes.

The next section reviews the key findings of the pilot and how they shaped the re-design of MALL resources in the course. The discussion concentrates on the essential concepts pertaining to the selection of a theoretical framework to guide the design of effective MALL solutions. A more detailed account of the individual questions, responses and data gathered during the pilot study can be found elsewhere (Palalas, in press).

\section{FINDINGS AND DISCUSSION}

As mentioned above, the level of students' satisfaction with the mobile technology and students' actual learning were measured throughout the study. All participants perceived the iPod Touch and other mobile devices to be an effective form of technology for ESP language learning and were highly satisfied with the MALL experience (Palalas, in press). They also emphasized the point that the flexible delivery format matched their needs and demanding schedules. Moreover, students self-reported that the m-learning practice helped them enhance their oral and aural skills. These observations were indeed confirmed by the CLBPT post-test, which revealed progress in both speaking and listening, with slightly higher listening results. Due to the blended character of the course, however, it was impossible to isolate whether it was the mobile learning component, specifically, that brought about the improvement in students' language proficiency.

Consistent with Mobile-Assisted Language Leaning (MALL) literature discussed earlier, the learners in this study seemed to enjoy using the mobile technology, the personalization it offered and learning "across contexts and life transitions" (Sharples, 2009). A number of advantages and disadvantages of MALL were identified, indicating that participants pre- 
ferred to rely on the inherent audio capabilities of the mobile devices rather than text-based options. In addition, students consistently cited flexibility, portability and convenience as affordances of the novel learning technology: "I don't need to make extra time for hearing because I could access anytime, anywhere." One student even reported: "Whenever I have extra time, I could listen and watch especially during driving or in the bus"; however this is not recommended behavior. More explicitly, learners listed the following opportunities as the key advantages of learning language with handled devices:

- learning on-the-go,

- listening to various podcasts whenever they chose to, as well as

- instant access to the Internet and other resources.

In fact, flexibility, on-demand retrieval and access to resources have all been identified as vital elements of MALL (Kukulska-Hulme \& Shield, 2008a), and should therefore be incorporated into the design of mobile language resources. In addition, respondents reported searching outside of the class curriculum for other free audio and video resources such as iTunesU accounting lectures or TED presentations. With their peers, students also exchanged ideas regarding free podcasts and introduced each other to language learning resources they found themselves. While students appreciated the opportunity for focused individual practice, there was a recurring theme of collaboration and peer support in their responses. Furthermore, newly-enhanced technical skills were identified as an extra benefit and the relevance of these skills for the workplace was acknowledged. A "coolness" aspect to using the mobile technology was reported as a factor that increased respondents' selfesteem in home life (with adolescent children), amongst other college students and in society at large.

A number of barriers to mobile learning were identified in the study as well. The cost of the device and connectivity were rated as the greatest limitations to the effectiveness of mobile learning technologies. Respondents also cited limited free wireless connectivity, difficulty typing on the small screen and short battery life as drawbacks in their ESP mobile learning experience.

From a pedagogical perspective, students expressed a need for more guidance in finding and selecting both the required and optional materials as well as free digital learning resources; for example, they asked for all resources to be labeled for importance and that a recommended order of completion be provided. Some students also commented that the amount of information was overwhelming; therefore, they needed pointers to the key resources and clear step-by-step instructions on how to use them. Notwithstanding the appreciation expressed for flexible self-paced learning and access to a myriad of free MALL resources, respondents stressed the fact that it was essential to have a facilitator and peer support. Students, indeed, indicated little desire or preparedness for independent learning that would translate into more flexibility yet less support, coordination, and encouragement coming from experts.

As found elsewhere in a CALL context (Hoven, 2003), these responses, together with the fact that the students were all experienced language learners, could suggest that, instead of working toward their own learning goals and applying their own learning strategies, students relied excessively on the expert guidance that was offered at the beginning of the course and then gradually removed as the course progressed. As a result, we intend to refine our MALL designs to include scaffolding support coming from both the facilitator and peers collaborating on group projects. In keeping with Ecological Constructivism, guidance should be available through interaction with peers, teachers, or the design and content of the mobile activity itself.

Moreover, to ensure the flexibility of mobile learning, our MALL tasks will combine face-to- 
face peer collaboration with computer- and phone-based follow-up activities. This design will also allow for enhanced oral and aural practice both in person and via digital channels. Bearing in mind that, consistent with their preference for audio over any text-based resources, students did not engage in mobile blogging activities on Wordpress, an option to record their audio reflections will be incorporated into the new MALL design. In fact, the few on-the-go blog entries were very brief and the majority of students opted to blog from their computers instead of their mobile devices, or not to blog at all. The time in front of the computer and the Wordpress Internet interface afforded more focused practice, richer editing and revision options. Students also indicated that the Wordpress blog interface was somewhat confusing and that it was much easier to wait until the face-to-face class meeting to exchange their reflections then.

These observations highlight a number of essential components of an effective MALL solution; namely, (1) a need for practicing both impromptu speech and reflection as well as rehearsed utterances, such as recorded audio reflections, (2) the natural tendency to conduct oral communication in person in a dynamic language environment, (3) the importance of a simple user-friendly mobile user interface, and (4) the enhanced access to resources available in dual web-based and mobile-accessible formats.

Further understanding of the design refinements which would offer more authentic and dynamic language practice, came from caveats in the MALL feedback. While students reported high satisfaction with the mobile technology, technical difficulties were, in fact, cited as a limitation to mobile learning. Students experienced some problems with the iPod Touches despite their self-reported previous experience with the technology, the orientation sessions provided on iTouch use, and other on-going technical support mechanisms. Despite the fact that technical problems were not rated as having significant importance in the question explicitly relating to the disadvantages of the iTouch technology, students were repeatedly observed expressing discomfort with the technology and its various functionalities. As indicated before, the fact that respondents did not own the devices also acted as a limitation. Students indicated that they would have experimented more with the iPod Touch if they owned the device.

Nevertheless, even given the general lack of experimentation, students did engage in a variety of language learning activities on their devices. The highest proportion of time was spent on listening to audio, downloading various podcasts, and browsing the internet, whereas less "mobile" time was devoted to the required activities involving blogging, watching video, emailing or typing notes. The latter were usually completed using computers. Students' engagement with aural activities on their mobile devices was consistent with their general desire for listening practice.

A common theme that emerged in all student feedback was the need to improve their listening and speaking abilities. Both teachers and students agreed that, of the four language skills, listening was the skill best addressed via the iPod Touch and other mobile devices used. A general observation of the students revealed that they were inclined to use those functions of their mobile devices with which they were most familiar and which, based on their previous experience with phones and mp3 players, they considered to be typical uses for a mobile device. Consequently, it can be concluded that additional instruction, practice and examples of usage of any novel technology functions would have to be introduced into MALL activities prior to students embarking on the actual language tasks. Such directions and practice of technology usage will be incorporated into the redesigned MALL resources.

Lastly, students and researchers alike observed that the resources developed for the pilot were not sufficiently engaging or interactive. When encouraged to communicate and reflect 
on the workplace videos, few students used their mobile devices to interact with others on the go. As noted above in the discussion of Ecological Constructivism, for learners to actively communicate with others outside of the classroom environment, mobile tasks have to be organized around meaningful goals and set in an environment that offers rich affordances. Such learning tasks serve to encourage purposeful search for linguistic material along with authentic, dynamic communication around the collaborative task. One way of facilitating dynamic oral interaction and the perception of affordances is to challenge learners to collaboratively collect language artifacts, such as audio or photos illustrating the meaning of a phrase. The mobile technology available to the learner can assist in pointing to and interacting with salient affordances present in the real-life environment. It can also serve as a communication channel that connects learners with resources, including other learners, facilitators, instructors or knowledgeable others and salient content.

\section{Some Limitations and Constraints of the Pilot Study}

The only limitations to this study stem from the students' familiarity with the researchers, the fact that they were offered access to the resources in this study free of charge and the small sample size. In addition, students' limited experience with the mobile devices might have influenced their experience in the study and therefore skewed the opinions they offered.

As a result of this study, it was recognized that further investigation of MALL design should include ESP students and practitioners from other programs at the College. Moreover, in order to minimize the self-efficacy barrier limiting students' experimentation with the mobile technology, future study participants should be using their own mobile devices. Other areas of on-going and future research will be discussed in the final section.

\section{CONCLUSION AND ONGOING RESEARCH}

Overall, high levels of student satisfaction with mobile technologies were reported during this pilot study of MALL in an adult ESP setting. As a result of this study, it has become evident that a sound pedagogical framework is vital in the design of Mobile-Assisted Language Learning, which is appealing, engaging and effective. In the educational setting presented here, L2 students were actively and vocally seeking opportunities to expand their language practice beyond the time and place constraints of the classroom, and they were surrounded by a myriad of English language affordances there to be acted upon in their environment. The framework conceptualized as Ecological Constructivism has therefore functioned as a critical lens in reformulating and refining the parameters of appropriate MALL models in the on-going DBR study.

Furthermore, a number of advantages and disadvantages of MALL were identified which indicated that participants found mobile listening superior to text-based resources and most convenient for on-the-go learning. Respondents observed, however, that integrating some written language support, such as transcripts, vocabulary and terminology sheets, might help them complete listening tasks. Students also admitted that although they greatly appreciated the mobile resources, and particularly the non-reciprocal audio podcasts, they experienced higher levels of motivation when interacting in the classroom.

The preference for non-reciprocal podcasts may also be indicative of the general lack of preparedness of students in this study for autonomous learning, as well as being a reflection of characteristics of their previous educational experience and background. In combination with the observation that the mobile resources were not adequately interactive, this feedback might point to the need for inclusion of ESP tasks which more transparently connect learners with others and with the environment/context in which they are situated 
and which are more relevant to them. These tasks and resources have to provide motivation and support for learning which the students experience when engaged in f2f discourse, and promote the level of social, cognitive and teaching presence possible in online learning, as described by Anderson, Rourke, Garrison, \& Archer (2001).

Having made this observation, some students explored their mobile devices and mobile connectivity to web-based resources, seeking support for individual language learning needs. This might indicate the preparedness of some students to participate actively in the selection and creation of their own learning resources. These observations then lead to the question of whether and to what extent student-generated resources can be part of the curriculum, considering how little autonomy in learning most students in this study exhibited. How much guidance and support from facilitators is required for students to engage and learn in a MALL-supported context? Other questions emerging from this study include:

- whether synchronous peer-to-peer communication is essential for learning listening skills;

- whether asynchronous communication would provide comparable learning experiences; and

- what support learners need in order to perceive and act on affordances in context.

These questions have now formed the basis of the ongoing investigation of the design of MALL listening content, including context-embedded affordances and the collaborative cocreation of resources.

As a result of the findings of this pilot study, the need has emerged to examine how the inherent audio capabilities and portability of mobile devices could take aural skills learning out of the classroom, while at the same time ensuring effective instruction. Design principles for effective MALL resources supporting the development of ESP listening skills, which were considered critical for the students in the pilot, are therefore the main focus of the current DBR study at George Brown College.

\section{NOTE}

${ }^{1}$ The CLB scale, comprising twelve benchmarks (CLB 1 to CLB 12 with Benchmark 12 indicating fluent advanced proficiency.), is descriptive and task-based. Each benchmark is comprised of a number of descriptors, performance conditions, performance indicators, tasks and competencies that serve as an indicator of a learner's language proficiency in each of the four skill areas - speaking, listening, reading, and writing.

\section{REFERENCES}

Abdous, M., Camarena, M., \& Facer, B. R. (2009). MALL technology: Use of academic podcasting in the foreign language classroom. ReCALL, 21(1), 76-95.

Alberta Learning - Language Training Programs \& Citizenship and Immigration Canada. (2004). Benchmarking adult rates of second language acquisition \& integration: How long and how fast? Final Report 2004. Retrieved from

http://www.language.ca/pdfs/Benchmarking\%20Adult\%20Rates\%20of\%20Second\%20Langua ge\%20Acquisition\%20and\%20Integration1.pdf

Anderson, T., Rourke, L., Garrison, D.R., \& Archer, W. (2001). Assessing teaching presence in a computer conferencing context. Journal of Asynchronous Learning Networks, 5(2), 1-17.

Bannan, B. (2009). The Integrative Learning Design Framework: An illustrated example from the domain of instructional technology. In T. Plomp \& N. Nieveen (Eds.), An introduction to 
educational design research (pp. 53-73). SLO: Netherlands Institute for Curriculum Development.

Business English Pod (n.d.). [English language learning website]. Retrieved from http://www.businessenglishpod.com/

Chinnery, G. M. (2006). Going to the MALL: Mobile assisted language learning. Language Learning and Technology, 10(1), 9-16.

CIITE (2004). The Colleges Integrating Immigrants to Employment (CIITE) Project. Implementing systemic change(Phase 3.1 - Final Report). Retrieved from The Colleges Integrating Immigrants to Employment (CIITE) project website: http://www.ciite.ca/en_home.asp

Davis, B. (2004). Inventions of teaching: A genealogy. Mahwah, NJ: Erlbaum.

Davis, B., \& Sumara, D. (2002). Constructivist discourses and the field of education: Problems and possibilities. Educational Theory, 52(4): 409-428.

Davis, B., \& Sumara, D. (2003). Why aren't they getting this? Working through the regressive myths of constructivist pedagogy. Teaching Education, 14(2): 123-140.

Downes, S. (2007). What connectivism is. Retrieved August 12010 from http://www.itdl.org/Journal/Jan_05/article01.htm

ESLpod (n.d.). English as a Second Language Podcast [English language learning website]. Retrieved from http://www.eslpod.com/website/index_new.html

Gibson, J. J. (1986). The ecological approach to visual perception. Hillsdale, NJ: Lawrence Erlbaum.

Halliday, M. A. K. (1993). Towards a language-based theory of learning. Linguistics and Education, 5(2): $93-116$.

Hoven, D. (1997). Improving the management of flow of control in computer-assisted listening comprehension tasks for second and foreign language learners. Brisbane: Unpublished doctoral dissertation, University of Queensland. Retrieved July 302009 from http://www.users.bigpond.net.au/cryptsoft/dlh/thesis/

Hoven, D. (1999). A model for listening and viewing comprehension in multimedia environments. Language Learning and Technology, 3(1), 88-103.

Hoven, D. (2003). Strategic uses of CALL: What learners use and how they react. Australian Review of Applied Linguistics Series S, 17, 125-148.

Hoven, D. (2006). Communicating and interacting: An exploration of the changing roles of media in CALL/CMC. CALICO Journal, 23(2), 233-256. Available at https://calico.org/journalTOC.php

iTunesU. (n.d.). [Web-based distribution system for educational content]. Retrieved from http://www.apple.com/education/itunes-u/

Jakobsdottir, S., McKeown, L., \& Hoven, D. (2010). Using the new information and communication technologies for the continuing professional development of teachers through open and distance learning. In P. Danaher \& A. Umar (Eds.), Teacher education through open and distance learning (pp. 105-120). Vancouver: Commonwealth of Learning.

Kiernan, P. J., \& Aizawa, K. (2004). Cell phones in task based learning: Are cell phones useful language tools? ReCALL, 16(1), 71-84.

Kukulska-Hulme, A. (2005). Introduction. In A. Kukulska-Hulme\& J. Traxler (Eds.), Mobile learning: $A$ handbook for educators and trainers. London: Routledge.

Kukulska-Hulme, A., \& Pettit, J. (2009). Practitioners as innovators: Emergent practice in personal mobile teaching, learning, work and leisure. In M. Ally (Ed.), Mobile learning transforming the delivery of education and training. Athabasca University: AU Press.

Kukulska-Hulme, A., \& Shield, L. (2008a). An overview of mobile assisted language learning: From content delivery to supported collaboration and interaction. ReCALL, 20(3), 271-289. 
Kukulska-Hulme, A., \& Shield, L. (2008b). Editorial. ReCALL, 20(3), 249-252.

Lafford, B. A. (2009). Toward an ecological CALL: Update to Garrett (1991). Modern Language Journal, 93(s1), 673-696.

Lam, W. S. E., \& Kramsch, C. (2003). The ecology of an SLA community in a computer-mediated environment. In J. Leather \& J. Van Dam (Eds.), Ecology of language acquisition (pp. 141-158). Dordrecht, The Netherlands: Kluwer Academic.

Laurillard, D. (2007). Pedagogical forms of mobile learning: Framing research questions. In Pachler, N. (Ed.), Mobile learning - towards a research agenda (pp. 153-175). WLE Centre, Institute of Education, University of London.

Nah, K. C., White, P., \& Sussex, R. (2008). The potential of using a mobile phone to access the Internet for learning EFL listening skills within a Korean context. ReCALL, 20(3), 331-347.

Pachler, N. (2009). Research methods in mobile and informal learning: Some issues. In G. Vavoula, N. Pachler, \& A. Kukulska-Hulme (Eds.), Researching mobile learning: Frameworks, tools and research designs (pp. 1-16). Bern, Switzerland: Peter Lang AG. International Academic Publishers.

Palalas, A. (2009). Using mobile devices to extend English language learning outside the classroom. In D. Metcalf, A. Hamilton, \& C. Graffeo (Eds.), mlearn2009: $8^{\text {th }}$ World Conference on Mobile and Contextual Learning. Proceedings (pp. 179-183). University of Central Florida.

Palalas, A. (in press). ESP for busy college students: Is the blend of in-class, online and mobile learning the answer? International Association of Language Learning Technology (IALLT) Journal.

Pawlikowska-Smith, G. (2000). Canadian Language Benchmarks 2000. English as a Second Language - for adults. Centre for Canadian Language Benchmarks. Citizenship and Immigration Canada.

Piaget, Jean. (1971). Psychology and epistemology: Towards a theory of knowledge. Translated by Arnold Rosen. New York: The Viking Press.

Proulx, J. (2006). Constructivism: A re-equilibration and clarification of the concepts, and some potential implications for teaching and pedagogy. Radical pedagogy, 8(1).

Rosell-Aguilar, F. (2007). Top of the pods - In search of a podcasting "pedagogy" for language learning. Computer Assisted Language Learning, 20(5), 471- 492.

Sharples, M. (2009). Methods for evaluating mobile learning. In G. Vavoula, N. Pachler, \& A. Kukulska-Hulme (Eds.), Researching mobile learning: Frameworks, tools and research designs (pp. 17-39). Bern, Switzerland: Peter Lang AG. International Academic Publishers.

Siemens, G. (2005). Connectivism: A learning theory for the digital age. Retrieved August 12010 from http://www.itdl.org/Journal/Jan_05/article01.htm

Spikol, D. (2009). Exploring learning practices through co-design of mobile games. In G. Vavoula, N. Pachler, \& A. Kukulska-Hulme (Eds.), Researching mobile learning: Frameworks, tools and research designs (pp. 123-136). Bern, Switzerland: Peter Lang AG. International Academic Publishers.

Strevens, P. (1988). ESP after twenty years: A re-appraisal. In M. Tickoo (Ed.), ESP: State of the Art (pp. 1-13). Singapore: SEAMEO Regional Centre.

TED (Technology, Entertainment, Design) (n.d.). [Web-based distribution system for presentations and talks]. Retrieved from http://www.ted.com/

Thornton, P., \& Houser. C. (2005). Using mobile phones in English education in Japan. Journal of Computer Assisted Learning, 21, $217-228$.

van den Akker, J., Gravemeijer, K., McKenney, S., \& Nieveen, N. (2006). Introducing educational design research. In J. van den Akker, K. Gravemeijer, S. McKenney \& N. Nieveen (Eds.), Educational design research: The design, development and evaluation of programs, processes and products (pp. 3-7). New York: Routledge. 
van Lier, L. (2000). From input to affordance: Social-interactive learning from an ecological perspective. In J. P. Lantolf (Ed.), Sociocultural theory and second language learning (pp. 245-259). Oxford: Oxford University Press.

Vygotsky, L. S. (1978). Mind in society: The development of higher psychological processes. Cambridge, MA: Harvard University Press.

Vygotsky, L. S. (1986). Thought and language. The Massachusetts Institute of Technology.

Wang, F., \& Hannafin, M. J. (2005). Design-based research and technology-enhanced learning environments. Educational Technology Research and Development, 53(4), 5-23.

Weinstein, N. (2001). Whaddaya say?: Guided practice in relaxed spoken English (2nd ed.). Pearson Education USA.

Wells, G. (1994). The complementary contributions of Halliday and Vygotsky to a 'language-based theory of learning'. Linguistics and Education 6 (1): 41-90.

Wertsch, J. V. (1985). Vygotsky and the social formation of mind. President and Fellows of Harvard College.

Wertsch, J. V. (1991). Voices of the mind: A sociocultural approach to mediated action. First Harvard University Press.

Wordpress [Web-based open source blog publishing application]. Retrieved from http://wordpress.org/

Zoomerang [Online survey software]. Retrieved from http://zoomerang.com/ 


\section{APPENDIX A}

Examples of Accounting Key Terms Featured in GBC Audio Podcasts (as per students handouts)

Kapoor, J., Dlabay, L., Hughes, R.J., and Ahmad, A. (2008). Personal finance (4 ${ }^{\text {th }}$ Canadian Ed.). McGraw-Hill Ryerson Higher Education.

\section{Chapter 1 (p. 26)}

\section{Bankruptcy - Bank-rupt-cy}

A set of federal laws that allow you to either restructure your debts or remove certain debts.

Inflation - In-fla-tion

A rise in the general level of prices.

Liquidity - li-quid-ity

The ability to readily convert financial resources into cash without a loss in value.

Opportunity cost - Op-por-tu-nity cost

What a person gives up by making a choice.

Present value

The current value for a future amount based on a certain interest rate and a certain time period; also referred to as discounting.

\section{Simple interest}

Interest calculated on the principal, excluding previously earned interest.

\section{Chapter 2 (p. 69)}

Assets

Cash and other property with a monetary value.

Cash flow

The actual inflow and outflow of cash during a given time period.

\section{Discretionary income}

Money left over after paying for housing, food, and other necessities.

Insolvency - In-sol-ven-cy

The inability to pay debts when they are due because liabilities far exceed the value of assets.

\section{Liabilities}

Amounts owed to others. 


\section{AUTHORS' BIODATA}

Debra Hoven is an Associate Professor in Distance Education at Athabasca University, Canada, where she teaches and supervises graduate research students in the areas of innovative pedagogies for online and mobile contexts, emerging approaches to instructional design for distance education, multimedia and digital storytelling and e-portfolio applications, particularly in aboriginal education and the evaluation of appropriate technology solutions in intercultural contexts. Another major research interest is the possible roles of social software and virtual worlds in promoting social and emotional cohesion in online learning and professional communities. Debra has considerable experience teaching languages and teacher education in Australia and several Asian countries and now teaches in the online Masters and Doctoral programs in the Centre for Distance Education.

Agnieszka Palalas is Lead Researcher and Curriculum Specialist at George Brown College, Toronto, Canada. She is a Doctoral Candidate at Athabasca University. As an early adopter of mobile technologies, she has been investigating Mobile-Assisted Language Learning (MALL) and the design of effective MALL activities since 2005. She has combined her expertise of instructional design, computer technologies and programming with 20 years of experience as a language instructor, to help second language learners meet their learning goals. Agnieszka holds a Master's Degree in Distance Education (Instructional Design, Program Development \& Educational Technologies), Advanced Graduate Diploma in Distance Education (Technology), Graduate Diploma in E-Commerce Solutions Developer (IT Programming), as well as a degree in Linguistics and Teaching English as a Second Language.

\section{AUTHORS' ADDRESSES}

Debra Hoven

Centre for Distance Education

Athabasca University

Alberta, Canada

Email: debrah@athabascau.ca

Agnieszka Palalas

Office of Academic Excellence

George Brown College

Ontario, Canada

Email: apalalas@georgebrown.ca 